\title{
USE OF BBC MICRO:BIT IN TEACHING TECHNICAL AND IT EDUCATION
}

\author{
Dragana Stanojević ${ }^{1}$ \\ Aleksandra Rosić2, \\ Branislav Ranđelović ${ }^{3}$ \\ Željko Stanković4
}

\author{
${ }^{1}$ Institute for Quality Evaluation of \\ Education, \\ Belgrade, Serbia \\ ${ }^{2}$ ITS Information Technology School, \\ Belgrade, Serbia \\ ${ }^{3}$ Faculty of Electronic Engineering, \\ University of Niš, Serbia \\ ${ }^{4}$ Institute for Improvement of Education, \\ Belgrade, Serbia
}

\begin{abstract}
:
Use of new teaching materials in technical and informatics education makes this subject easier to understand and more meaningful to learn. This paper describes use of miniature computers Micro:bit and its characteristics, developed by the British company BBC in cooperation with several technology companies, with purpose to increase the number of technologically educated people. Paper presents possible use of Micro:bit in teaching technical and informatics education and its impact on development of digital competence. Micro:bit is being used in schools in the UK and part of teachers in Serbia had the opportunity to get acquainted with characteristics of the device. It has been shown how students can try out the programming in the Microsoft Block Editor. Another benefit of this mini-computer is getting to know the basics of robotics. The curriculum in primary education enables the use of such tools in educational work with students. Use of this tool and other similar to it in the work with students creates the atmosphere that is oriented towards new technologies. Simplicity of mini computers allows student to become familiar with different professional challenges that can help them with choosing a future profession.
\end{abstract}

Keywords:

BBC Micro:bit, teaching tool, new technologies, primary education, technical and informatics education.

\section{INTRODUCTION}

Modern society expects education to prepare future citizens of the world for the technology that will be used in the future. Also, no one can predict which way technology will develop and prosper over the next 10 , let alone 50 years. In the mid-seventies of the last century, an average person could not have guessed that the technology would be publicly and widely available; that man would be replaced by computers or robots in many areas; that many professions would almost disappear and new ones would appear- those that would make some individuals the richest people of the world in a very short time. The auto industry has invested a lot of money in order for the innovative technologies to improve various aspects of this area [1]. 


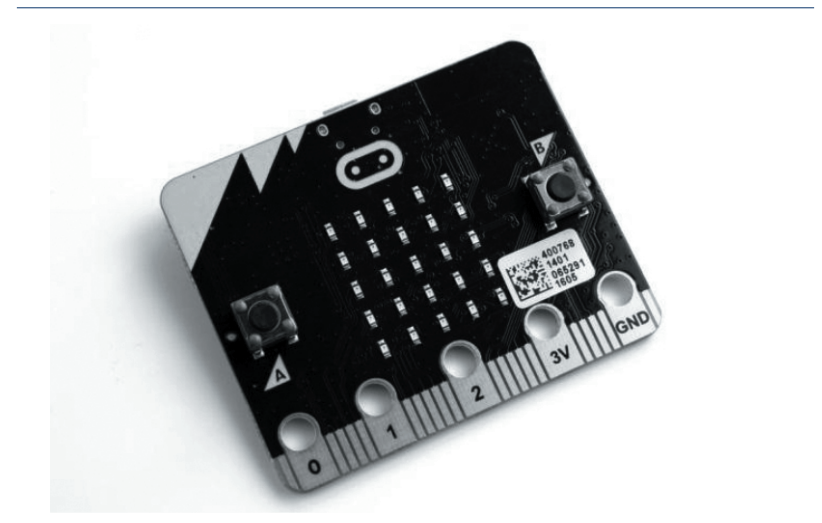

Fig. 1. Image BBC micro:bit.

Innovation of teaching materials enables students to use modern technology, which will help them to familiarize themselves with new developments that are rapidly alternating. The BBC company, in collaboration with several other companies, engaged in technology, has developed a miniature device called the BBC Micro: bit. Figure 1 shows the image of the miniature device. Over a million students in the UK use this device and its use at schools become part of the curriculum.

Education of students is moving in the direction of developing a logical apparatus that will enable them to evolve in the role of users, and to get prepared for life in a world where the change is the only constant.
Learning the information technology enables students to:

- know how to search, assess the relevance and reliability, analyze, systematize information in electronic form using the appropriate ICT resources (equipment, software products and e-services).

- know how to express themselves in electronic form using appropriate ICT resources, including multimedia expression and expression with elements of formally defined notation used for the characteristic means of ICT (E.g., address, requests, commands, of the formula, and the like procedures, expressed in appropriate notation).

- use ICT to play, organize, structure and format information using the opportunities given by ICT resources in an efficient manner.

- know how to choose appropriate ICT resources, as well as to adapt the way of problem solving capabilities of these ICT assets.

- use ICT for communication and cooperation.

- recognize the risks and dangers in the use of ICT.

Table 1 [2] shows a part of the Scottish curriculum related to Computing science contexts for developing technological skills and knowledge.

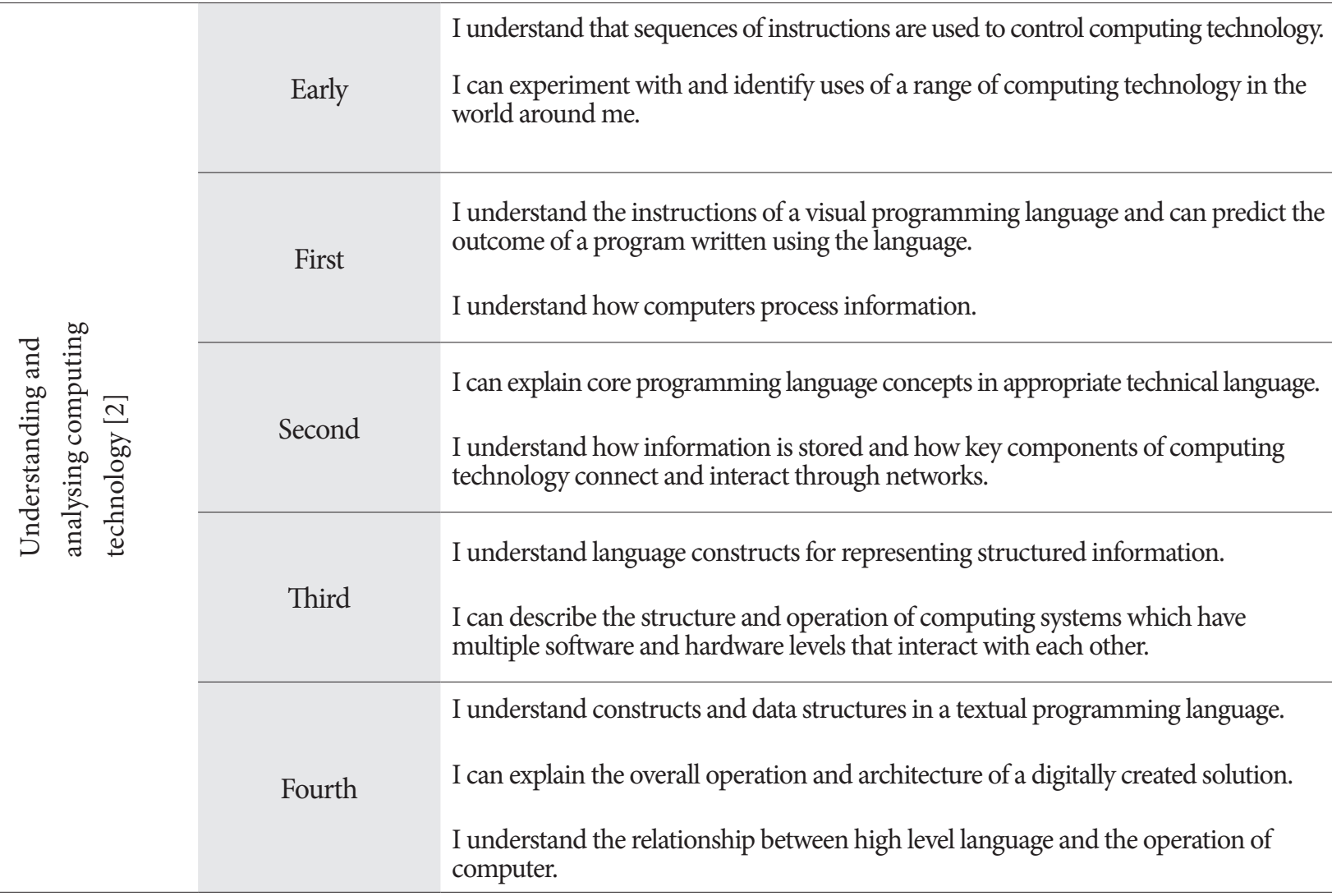

Table 1. Computing science learning outcomes in the Curriculum for Excellence Technologies: experiences and outcomes [2] 
This device is designed to help students aged 8 to 13 years to become familiar with algorithmic thinking, science, especially with coding, programming, game development and robotics. Such devices where students have the opportunity to create their own specific content stimulate creativity and develop the entrepreneurial spirit. One of the most important roles of the $\mathrm{BBC}$ micro:bit is to introduce students to the way games are developed. In this way we have a chance to show students that creating a game is not just entertainment, but commitment and creativity.

\section{TECHNICAL CHARACTERISTICS}

$\mathrm{BBC}$ micro:bit is a small device that can be placed in a pocket, its production is low-cost, and because of the size of the device, its transport is easy and it can easily become accessible to a large number of students. Basic characteristics of the micro:bit [3] device are:

- 25 red LEDs to light up, flash messages, create games and invent digital stories.

- Two programmable buttons are activated when pressed. It can use the micro:bit as games controller. It pauses or skips songs on a playlist.

- there is an on-board motion detector or "accelerometer" that can detect movement and tell other devices you're on the go. Featured actions include shake, tilt and freefall. Turn the micro:bit into a spirit level. Light it up when something is moved. Use it for motion-activated games.

- A built-in compass or "magnetometer" is there to sense which direction you're facing, your movement in degrees, and where you are. Includes an in-built magnet, and can sense certain types of metal.

- Bluetooth Smart Technology to connect to the internet and interact with the world around you. Connect the micro:bit to other micro:bits, devices, kits, phones, tablets, cameras and everyday objects all around. Share creations or join forces to create multi-micro:bit masterpieces. Take a selfie. Pause a DVD or control your playlist.

- Five Input and Output (I/O) rings to connect the micro:bit to devices or sensors using crocodile clips or $4 \mathrm{~mm}$ banana plugs. Use the micro:bit to send commands to and from the rings, to power devices like robots and motors.

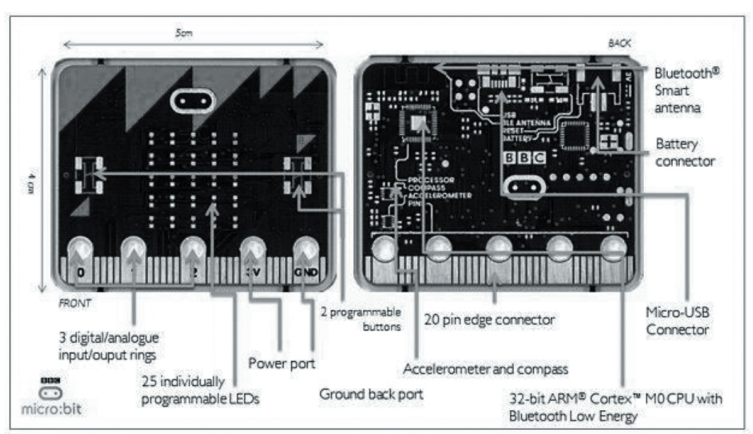

Fig. 2. The BBC micro:bit front and back [3].

\section{DEVICE OPTIONS}

Using micro:bit in the classroom can develop the following ICT topics: creating simulations of physical systems; making algorithms that respond to different inputs and give different outputs; solving the same problem using different tools and coding languages; storing and manipulating data; introducing Boolean logic and operators to students; connecting multiple computer systems together and using technology in art. Students can use this device in a very simple way with good guidance by the teacher. Microsoft developed web application and hosting service- all micro:bits share a one website and users can choose which code they will be use. Programming is allowed in:

1. JavaScript editor makes it easy to program micro:bit in Blocks and JavaScript, along with great new features like peer-to-peer radio. (Fig. 3.)

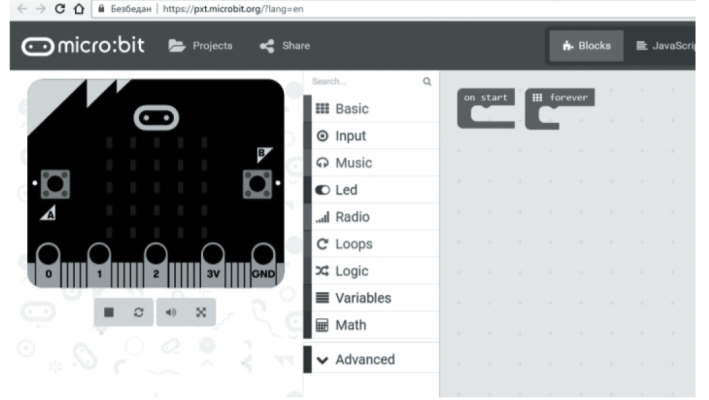

Fig. 3. Show JavaScript editor.

2. Python editor (Fig. 4.) is perfect for those students who want to move their coding skills further. A selection of snippets and a range of premade images and music give student a helping hand with their code. 


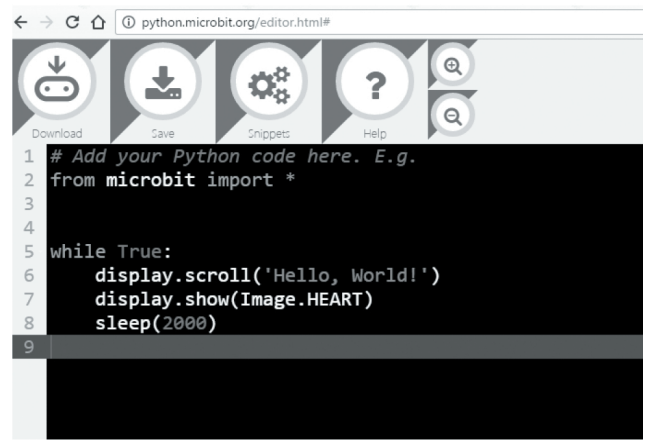

Fig. 4. Show Python editor.

Before a student compiles micro:bit script he can run it using the micro:bit simulator, after successful simulation transfers code on a device.

\section{APPLICATION IN TEACHING IT IN PRIMARY EDUCATION}

The overall objective of teaching informatics and computer science is that students are trained to use computers and acquire skills in the application of computers in everyday life, exploring the basic concepts of informatics and computing, developing interest in the use of computers in everyday life and work, training for computer work, as well as encouraging creative work on the computer.

In primary education, within the subject of informatics, students have the opportunity to independently create a project that is either part of the contents of a subject that is taught during the training or other content that they can choose independently. Drafting terms of reference - Micro:bit, should be set as a target. For the realization of the project task, students use the knowledge acquired in the course Informatics and Computing. The project can be implemented individually or in groups of two to three students. If students work in a group, teacher should clearly define the tasks and unities for each student that he/she will work on independently. The assumption is that school has a Micro: bit device, and that students have the Internet access.

A teacher instructs students on how they can explore the possibilities of Micro: bits and then directs them to the Instructions on the safe use of Micro bit [5]. (Fig. 5.)

Teacher also instructs students about [5]:

Requirements - A laptop or PC running Windows 7 or later, or a Mac running OS X 10.6 or later, or a smart phone or tablet, An micro USB cable to connect computer and $\mathrm{BBC}$ micro:bit to access to the Internet [5]:

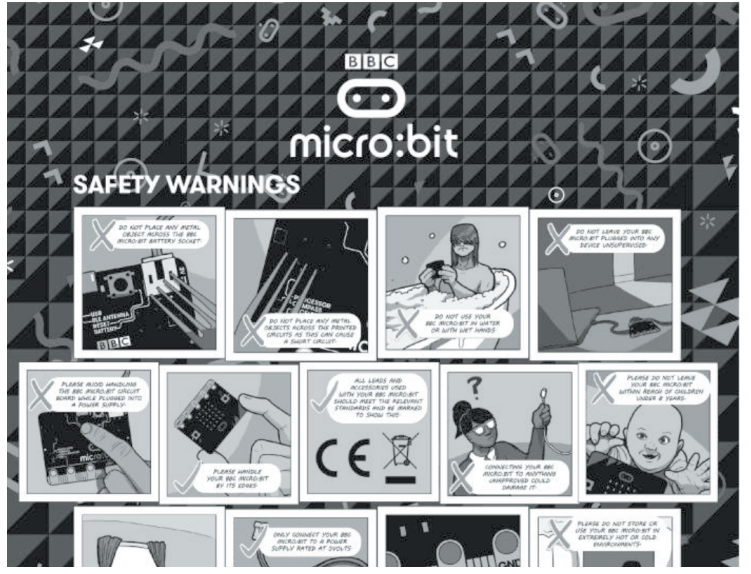

Fig. 5. Part of the instructions on the safe use of Micro: bits.

Accessing the BBC micro:bit website - There are lots of tutorials and information on the website.

Connecting to computer and coding micro:bit Students can connect their micro:bit to computer with a micro USB cable. On the website, student can choose the editor that they would like to code with. When they have finished their script, they can press run to see it playing on the on screen simulator.

Compiling script - By clicking compile in the editor, students script is converted into a .hex file that can transfer and run on BBC micro:bit. If students want to compile a different script they should click on My Scripts, select the wanted script, click edit and compile.

Transferring the file to BBC micro:bit - Students should drag and drop the hex file onto your micro:bit drive. The LED on the back of micro:bit flashes during the transfer which only takes a few seconds; once transferred, the code will run automatically on your micro:bit. Once the transfer of a file is finished, the BBC micro:bit can be disconnecting from computer.

Powering BBC micro:bit - When $\mathrm{BBC}$ micro:bit is not connected to computer with a USB, it needs $2 \mathrm{x}$ AAA batteries to power it.

Using phones and tablets - Students can find out how to use the $\mathrm{BBC}$ micro:bit App to connect their phones and tablets with the $\mathrm{BBC}$ micro:bit in the getting started section on the website.

In the process of monitoring project development, the teacher can talk with the students about the concept of copyright, draw attention to the ways of sharing digital materials, i.e. methods of downloading other people's material and setting up their own material on the Internet. Recommended number of hours is six to eight hours for these activities. Teachers should monitor students in 
their work and encourage them to work independently. Project should be displayed and presented to the whole class or wider community. The presented results, as well as problems and solutions, should be commented on and analyzed together with students.

\section{CONCLUSION}

Until recently, the digital world has been a small part of our lives, clearly separated from the "real" world, in which, out of obligation or for fun, relatively few were leaving and staying relatively short. Today, digital world pervades our overall living and working space to the extent that digital illiteracy dramaticly handicaps and marginalizes an individual. Using the BBC Micro: bit in teaching is designed so that students independently create notions in digital world and become familiar with the basics of programming, as well as find some information that will enable them to continue learning independently.

BBC Micro: bit should not be considered as a mean by which students will master programming, but as a device used for setting foot in the world of programming and thinking about own future professional development.

In the 12th Century, it was mostly the clergy who could read or write, but increasing administration made literacy much more widespread (everyone began keeping books). He believes that all professional men (doctors, lawyers, surgeons, scriveners, schoolmasters), $20 \%$ of tradesmen, as well as many freeholders, were literate. Mortimer estimates that general literacy was $20 \%$ in the towns, whereas $5 \%$ in the countryside [6].

Nowadays, so many centuries after the mentioned period, the same can be said for computer literacy. It is a necessity for anyone who wants to develop professionally, learn or simply operate within the analog world that is more and more pervasive digitalised.

Let's encourage students to create their first system, something never built before, to spark their interest. [8]

\section{REFERENCES}

[1] S. H. Thomke, "Research Program on Global Automotive Development" in Experimentation matters: unlocking the potential of new technologies for innovation, 3th ed, Harvard Business Shool, Boston, Press, 2003.

[2] 2017. [Online]. https://www.education.gov.scot Available: (https://www.education.gov.scot/Documents/technologies-eo.pdf)

[Accessed 15. 4. 2017]

[3] T. Ball, J. Protzenko, J. Bishop, M. Moskal, J. de Halleux, \& M. Braun, M. The BBC micro: bit coded by Microsoft Touch Develop. Microsoft Research. (2016).

[4] D. Renton, The Importance of Computer Games Development in the Computing Curriculum in Schools, The Computer Games Journal September 2016, Volume 5, Issue 1, pp 1-5 (2016).

[5] 2017. [Online]. www.microbit.net Available: https:// microbit.org/assets/documents/student-safteyguide.pdf [Accessed: 4- Mar- 2017].

[6] I. Mortimer, The time traveller's guide to Elizabethan England. Random House. (2013)

[7] http://www.bbc.co.uk/programmes/articles/4hVG 2Br1W1LKCmw8nSm9WnQ/the-bbc-micro-bit (pristupljeno strani 2. aprila 2017.)

[8] A. Schmidt, "Increasing Computer Literacy with the BBC micro:bit" in IEEE Pervasive Computing, vol. 15, no. 2, pp. 5-7, Apr.-June 2016. 